\title{
A Study of the Development of a Concrete Floating Breakwater for an Open Sea Fish Farm
}

\author{
Gun-Hwan Choi®*, Mi-Jeong Kim $\circledast^{*}$, Ki-Ho Jang $\circledast^{*}$, Je-Cheon Jun $\circledast^{* *}$ and Jung-Jun Park $\circledast^{* *}$ \\ "Department of Mechanical Engineering/Floating offshore wind power farm field, POSTECH, Pohang, Korea \\ *Aquaculture Research Division, National Institute of Fisheries Science, Busan, Korea

\section{외해 양식장 콘크리트 부유식 방파제 개발에 관한 연구}

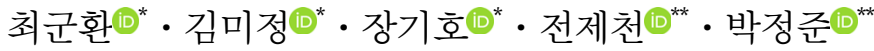 \\ "포항공과대학교 기계공학과/부유식해상풍력발전연구소 \\ "국립수산과학원 양식관리과
}

KEY WORDS: Ocean condition 해양조건, Structure analysis 구조물 해석, Towing tank test 수조시험, Concrete floating breakwater 콘크 리트 부유식 방파제, CAPEX 설비투자비, Fish farm 양식장

\begin{abstract}
The ecological changes in the ocean due to the drastic global warming require that action be taken to sustain the productivity of fisheries. Proper ocean facilities could help prevent the loss of the expenditures made on marine aquaculture and reduce the related compensation for various ocean conditions. The aim of this study was to develop a floating ocean wave-breaker using an eco-friendly concrete and conducting a site survey, a structural analysis, and a test of towing the tank. As a result, the wave at the fish farm would be reduced. The results of the holding power of anchors and the capability of moving the floating structures were considered in the design of the wave-breaker. The analyses of the material properties of concrete and the steel structures, as well as the CAPEX and OPEX analyses of the manufacturing and operation processes confirmed the superiority of the floating concrete wave-breaker. In particular, this study demonstrated that the concrete floating breakwater can protect the fish farm against typhoons and reverse-waves, thereby reducing losses of the fish.
\end{abstract}

\section{1. 서 론}

지구 온난화로 인한 태풍 및 기상 이변은 수산 자원 지속 생 산을 통한 식량화의 시급성을 요구하고 있다. 이러한 환경 속에 서 수산물 거대 소비 시장을 겨냥한 외해 양식장의 대형화는 양식장 피해 보상 규모를 증대시키고 있다. 이러한 상황에서 부 유식 방파제는 외해 양식장을 보호할 수 있는 중요한 구조물로 각광받고 있다. 부유식 방파제는 입사하는 파도를 차단하면서 태풍과 같이 큰 파도를 견뎌내야 하는 구조물이다. 국내에도 부 유식 방파제는 2007년 통영시 바다 목장 전면 해역을 시작으로 여러 해역에 설치되어 오고 있다.

부유식 방파제는 바다 낚시터와 같은 친수 공간으로도 활용 되고 있다(Kim et al., 2007a). 양식장 보호 뿐만 아니라 어항 및 항만 보호, 그리고 해양 공사 기간 동안 소파의 용도로도 많이 이용된다(Jung et al., 2006). 부유식 방파제는 해당 해역의 환경 특성을 감안하여 해양 시설물이 위치한 해역에서 원하는 정온
도(Tranquility)를 확보하도록 설계되어야 한다. 그래서 해양 지 역에 따른 부유식 방파제의 소파 성능을 정확하게 예측하는 연 구가 동시에 요구되고 있다(Cho, 2002).

소파제는 해역 보호를 위하여 파랑 에너지를 소산시키는 구 조물을 의미하며 일반적으로 방파제로 알려져 있으며, 고정식 소파제 (중력식 소파제)와 부유식 소파제로 구분된다. 부유식 소파제는 중력식에 비해 대수심 및 연약지반에 적합하고 시공 이 간단하여 건설비가 절감되며 수심이 $10 \mathrm{~m}$ 가 깊어지면 설치 비용의 급격한 차이를 보이다. 또한, 지진 피해가 적고 필요시 이동이 가능하며 방파제 역할 이외에 낚시터 등 관광 목적으로 도 활용할 수 있다(Jung et al., 2006).

국내에서는 2007년 상반기 최초로 통영시 바다 목장 전면 해 역을 대상으로 부유식 방파제를 설치하였으며, 하반기에는 마 산시 원전항에 신형식 복합 판형 부유식 방파제를 건설하였다. 마산시 원전항의 경우 해역 수심은 $20 \mathrm{~m}$ 로 국내외에서 최초로 닺 블록 대신 석션 닺을 현장에 적용했다는 데 의의가 있으나

Received 14 November 2019, revised 7 December 2019, accepted 19 December 2019

Corresponding author Gun Hwan Choi: +82-52-279-9023, kingsunchoi@postech.ac.kr ORCID: http://orcid.org/0000-0003-2845-180X

(c) 2019, The Korean Society of Ocean Engineers

This is an open access article distributed under the terms of the creative commons attribution non-commercial license (http://creativecommons.org/licenses/by-nc/3.0) which permits unrestricted non-commercial use, distribution, and reproduction in any medium, provided the original work is properly cited. 


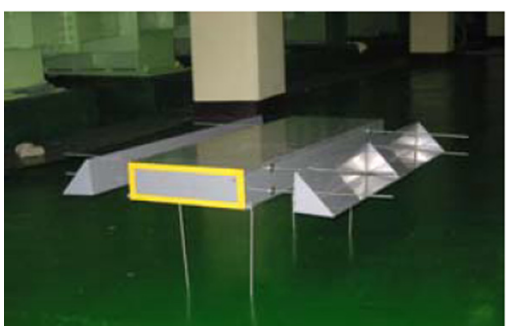

(a) Composite plate breakwater model

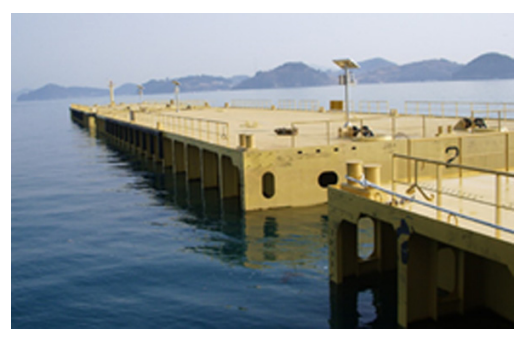

(b) Yeonmyeongport

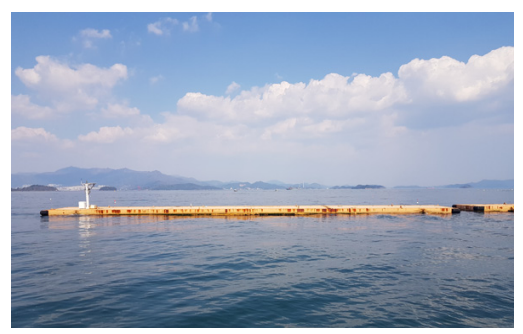

(c) Wonjeongport
Fig. 1 Domestic floating breakwater case

파고 $1 \sim 1.5 \mathrm{~m}$ 방지기능이 한계가 있다. Fig. 1은 통영시 및 마산 시에 설치된 부유식 방파제의 제작 모형과 전경을 나타낸 것이 다(Kim et al., 2007a; Kim et al., 2007b).

부유식 방파제는 설치 해역에서 발생하는 파랑 하중에 의한 굽 힘 모멘트와 전단력을 충분히 지탱할 수 있는 우수한 구조 성능을 가져야 한다. 이러한 이유로 과거 부유식 방파제의 소재는 주로 강재였으나, 강재의 경우 대형화를 위해서 경제성이 낮은 문제점 을 가지는 것으로 알려져 있다. 연명항 및 원전항 부유식 방파제는 강재 재질이며, 당항포 방파제는 콘크리트 부유식 방파제이다.

부유식 방파제는 시공 과정에서의 작업성 및 경제성 확보를 위한 구조 형식을 가져야 하며 콘크리트 부유체의 경우 인장 하중에 취약하므로 이에 견딜 수 있는 능력을 지녀야 한다 (Jeong et al., 2013; Park and Youn 2016; Link and Elwi, 1995). 부유식 방파제를 콘크리트로 제작할 경우 강재에 비해 제작비 용은 약 $46 \%$, 유지관리비용은 $90 \%$ 이상 절감이 가능하며, 적절 한 중량으로 가장 경제적 - 친환경적 - 안정적 재질로 주목받고 있다. Fig. 2는 강재 부유체, 콘크리트 부유체 등의 시공 비용을 도식화한 것으로 콘크리트 부유식의 경우 상대적으로 수심이 깊어지더라도 시공 비용은 큰 영향이 없음을 알 수 있다. 하지 만 해상 콘크리트 구조물은 육상보다 상대적으로 해수, 저온, 염해 등 해양 환경에 민감하다(Jeong et al., 2013; Koh et al., 2004). Fig. 2에 표현된 기준으로 콘크리트는 수심이 없는 상태 로부터 180 원 $/ \mathrm{m}^{2}$ 로 공사비가 유리하고, 최대 수심 $50 \mathrm{~m}$ 일 때 비 교 분석 결과는 강재 580 원 $/ \mathrm{m}^{2}$, 콘크리트는 320 원 $/ \mathrm{m}^{2}$ 로 확인되 어 강재와 비교하여 약 $56 \%$ 수준이다. 특히 수심이 깊어질수록 원가 격차가 현저하게 발생한다.

최근 콘크리트의 단점을 극복하기 위한 기술 개발로 인하여

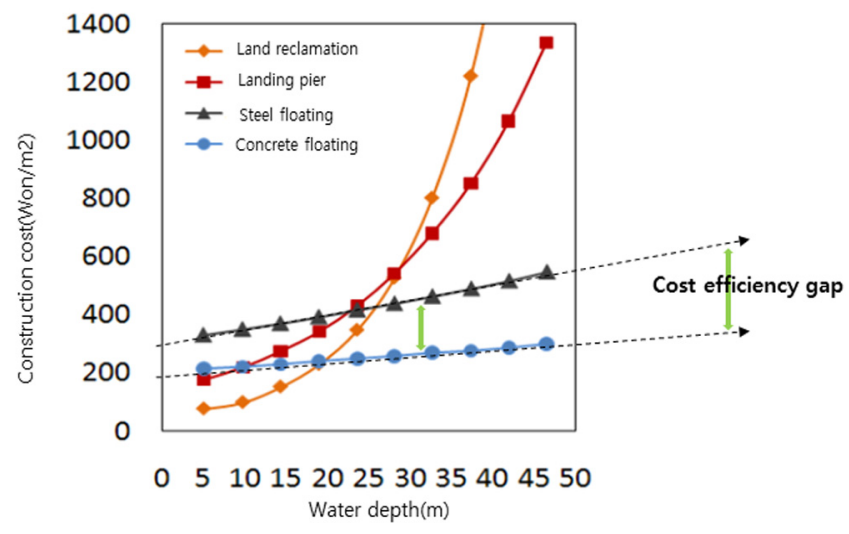

Fig. 2 Construction cost by types of marine spaces
콘크리트 소재도 많이 활용되고 있다. 본 연구는 국내 해상 조 건에 맞는 콘크리트 소재의 부유식 방파제를 개발하고 실제 해 역 설치를 목적으로 한다. 부유체 기본 설계를 위하여 수계산을 통한 동수력을 산정하였고 기초적인 보 계산을 통하여 기본 설 계를 확정하였다. 두 가지 크기의 부유체(유닛 I 과 유닛 II)를 기본 설계하였으며 소재에 따른 응력 계산을 통하여 콘크리트 소재의 부유식 방파제의 구조 성능을 검증하였다. 또한, 부유식 방파제 계류를 위하여 요구되는 닺의 모형에 대한 육상 압흔 실험을 통하여 닻의 표면 요철 문양에 따른 성능을 검증하였으 며, 닻 모형의 수조 예인 실험을 통하여 예인 능력의 차이를 검 증하였다. 이를 통하여 최적의 닺 유형을 제시하였다. 마지막으 로 강재 및 콘크리트 부유식 방파제의 경제성 비교를 통하여 콘크리트 부유식 방파제의 우수성을 확인하였다.

\section{2. 부유식 방파제 기본 설계}

\section{1 설치 해역 해상 조건}

본 연구의 설치 대상지는 경남 통영시 욕지면의 본 섬에 해당 하는 욕지도이며 면적 $12.62 \mathrm{~km}^{2}$ 로 욕지면 관할 도서 중 가장 크 다. 부유식 방파제를 설치할 대상 해역인 욕지도 서산은 외해 양식장 2 개소 $\left(350,000 \mathrm{~m}^{2}\right)$ 를 포함하여 참다랑어, 참돔 등의 고급 어종 양식장이 밀집된 구역이다.

대상 해역의 수심은 현장 조사를 통하여 실측되었으며, 최저 $20 \mathrm{~m}$ 및 최대 $52 \mathrm{~m}$ 였다. 또한, 최고 조위와 최저 조위는 각각 $325 \mathrm{~cm}$ 및 $-46 \mathrm{~cm}$ 로 조사되었다. 부유식 방파제 설치 대상 해역 에 인접한 욕지 관측소 계측 자료를 2019년부터 활용하여, 정상 조건(Normal condition)에 대한 파고 및 파주기를 결정하였다. 태 풍 볼라벤에 관한 기록을 검토하여 극한 조건(Extreme condition) 에 상응하는 파고 및 파주기를 결정하였다. 이에 상응하는 규칙 파 속성을 Table 1에 제시하였다. 또한, 0 도부터 90 도까지 22.5 도 간격으로 파향(Wave incident angle)을 고려하였다(Fig. 3).

Table 1 Design Criteria for floating breakwater inspection data

\begin{tabular}{cccc}
\hline \hline \multirow{2}{*}{ Water depth } & \multicolumn{3}{c}{ Wave characteristic } \\
\cline { 2 - 4 } & Item & Normal & Extreme \\
\hline \multirow{3}{*}{$40-50 \mathrm{~m}$} & Wave height & $7 \mathrm{~m}$ & $12 \mathrm{~m}$ \\
& Period & $9 \mathrm{~s}$ & $9 \mathrm{~s}$ \\
& Wave length & \multicolumn{2}{c}{$122.33 \mathrm{~m}$} \\
& Wave speed & \multicolumn{2}{c}{$13.593 \mathrm{~m} / \mathrm{s}$} \\
\hline
\end{tabular}




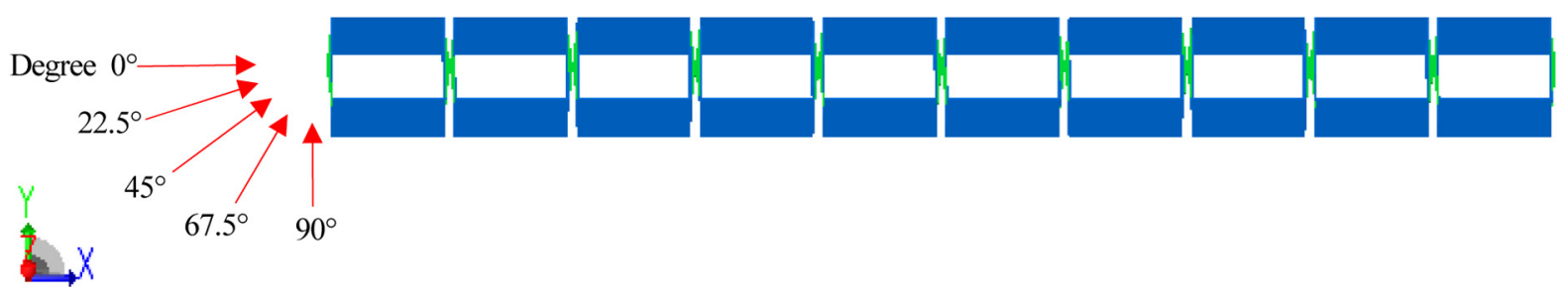

Fig. 3 Floating breakwater and wave direction

\section{2 부유식 방파제 기본 설계}

본 연구에서는 부유식 방파제 기본 설계를 위하여 Table 2에 기본적 수리학적 이론을 정리하였다. 유체에 잠긴 면에 작용하 는 합력 $\left(F_{R}\right)$, 잠긴 평면이 받는 힘의 작용점 $\left(y^{\prime}\right)$, 잠긴 물체에 대한 유체의 부력은 배제된 유체의 무게와 같고 물체 위치의 안정성을 고려한 부력 $\left(F_{\text {buoyancy }}\right)$ 이론 그리고 부유체의 배수량, 수선 면적 등을 계산하기 위해 Simpson 법칙을 응용하였다.

물을 이상 유체로 가정하여 선형 수면파 이론을 적용하였으 며, 수면파 파형 $(\eta)$, 속도포텐셜 $(\phi)$ 과 무한 수심에서의 각속도 $(\omega)$, 파수 $(k)$ 의 관계를 분산 관계식(Dispersion relation)으로 정리 하였다. 물 위에 떠 있는 부유체는 서로 다른 매질(공기, 물)속 에 있어 고정된 횡동요(Rolling) 축이 없지만, 횡동요 축이 중심 점 부유체 무게 중심(Center of gravity, $\mathrm{COG}$ )를 관통한다고 가정 하여 배의 운동방정식과 횡동요 주기 $T_{\phi}$ 의 기초식을 정의하였 다. 메타센터 거리(Metacentric height, GM)는 횡동요 주기를 결 정하며 복원력을 결정하는 중요한 인자이다(Fox et al., 2017;
Lee, 2012; Lee, 2014; SNAME, 1991).

이와 같은 환경 조건과 동수력 이론 계산 결과를 바탕으로 부 유식 방파제의 주요 치수를 결정하였다. 부유식 방파제를 크기 에 따라 유닛 I 과 유닛II로 구분하여, 주요 치수, 중량, 체적, 표면적 등의 주요 정보를 Table 3에 나타내었다. 유닛 I 는 정사 각형 플로어(Floor) 및 유닛 II는 직사각형 플로어 형태이며, 유 닛 I 은 보강보(Reinforced beam)와 보강벽(Reinforced wall)이 설 치되며, 유닛 II 는 보강벽만 길이의 중앙에 존재하여 구획을 형 성한다. 두 구조물 사이의 중량 차이는 $757 \mathrm{t}$ 이다. 부유식 방파제 1 세트는 10 개 유닛으로 구성된다.

유닛 1 개당 4 개의 계류선에 의하여 계류되며, 각 계류선의 해 저면에 닺(Anchor)이 설치된다. 본 연구에서 적용한 닺은 액티 브 닺(Asterina anchor)과 투묘식 콘크리트 닺(Centipede anchor) 이다. 각각의 중량은 대략 $40 \mathrm{t}$ 및 $65 \mathrm{t}$ 이다. 1 개 유닛에는 개구부 (Opening hole), 계류선과 연결되는 파이프, 파랑 에너지 소산을 위한 소파벽(Wave absorbing wall), 유닛 사이의 파형 접합부

Table 2 Fundamental formulas for hydrostatic and hydrodynamic calculations

\begin{tabular}{|c|c|c|}
\hline Classification & Main formula & \\
\hline Hydrostatic force & $\begin{array}{l}\text { Buoyancy : } F_{B}=\rho g V \\
\text { Resultant force }: F_{R}=\int_{A} p d A \\
\text { Acting point of force }: y^{\prime}=y_{c}+\frac{\rho g \sin \theta I_{\hat{x} \hat{x}}}{F_{R}}\end{array}$ & $\begin{array}{l}\rho: \text { density of seawater } \\
g: 9.81 \mathrm{~m} / \mathrm{s}^{2}, \quad V: \text { volume, } \\
p: \text { hydraulic pressure } \\
A: \text { area, } y^{\prime}: \text { center distance of hydrostatic } \\
\text { pressure, } y_{c}: \text { y coordinate of centroid } \\
\theta: \text { angle, } I_{\hat{x} \hat{x}}: \text { geometrical moment of inertia }\end{array}$ \\
\hline Simpson's rule & Waterplane area : $A=\frac{8 h}{3}\left(y_{1}+3 y_{2}+3 y_{3}+2 y_{4} \ldots 3 y_{n-1}+y_{n}\right)$ & $h=x_{n}-x_{n-1}$ \\
\hline $\begin{array}{l}\text { Airy wave theory } \\
\text { (Linear water } \\
\text { surface waves) }\end{array}$ & $\begin{array}{l}\text { Surface wave shape }: \eta(x, t)=A \cos (k x-\omega t)=A \cos \Theta \\
\text { Velocity potential }: \phi(x, y, t)=\frac{g A}{\omega} e^{k y} \sin (k x-\omega t) \\
\text { Dispersion relation }: \omega^{2}=g k\end{array}$ & $\begin{array}{l}\eta: \text { surface wave shape, } t: \text { time, } g: 9.81 \mathrm{~m} / \mathrm{s}^{2} \\
k: \text { wave number, } \Theta: \text { phase function } \\
\omega: \text { circular frequency } \\
A: \text { amplitude of surface wave }\end{array}$ \\
\hline Ship motion & $\begin{array}{l}\text { Equations of motion : } I \frac{d^{2} \phi}{d t^{2}}+M=0 \\
\text { Rolling period : } T_{\phi}=\frac{1.108 k}{\sqrt{G M}}\end{array}$ & $\begin{array}{l}M: \text { restoring moment, } \phi: \text { velocity potential } \\
I: \text { mass moment of inertia, } t: \text { time } \\
G: \text { center of gravity, } k: \text { mass inertia radius }\end{array}$ \\
\hline
\end{tabular}

Table 3 Specifications of floating breakwater unit I and unit II

\begin{tabular}{ccccccccccc}
\hline \hline \multirow{2}{*}{ Floating body } & \multicolumn{3}{c}{ Principal dimensions [m] } & \multicolumn{3}{c}{ Weight [t] } & \multicolumn{3}{c}{ Geometric properties } \\
\cline { 2 - 11 } & $L$ & $B$ & $D$ & $T$ & Total & Concrete & Rebar & $S_{t}\left[\mathrm{~m}^{2}\right]$ & $S_{f}\left[\mathrm{~m}^{2}\right]$ & $V_{t}\left[\mathrm{~m}^{3}\right]$ \\
\hline Unit I & 15.0 & 15.0 & 10.3 & $2 / 8$ & 1,551 & 1,354 & 199 & 2,550 & 225 & 572 \\
Unit II & 15.0 & 10.0 & 5.0 & $1.5 / 3.5$ & 757 & 690.3 & 66.7 & 1,406 & 165 & 251 \\
\hline
\end{tabular}

$L$ : Length of unit, $B$ : Breadth of unit, $D$ : Depth of unit, $T$ : Freeboard/Draft of unit, $S_{t}$ : Total surface area of unit, $S_{f}$ : Total floor area of unit, $V_{t}$ : Total volume of unit 

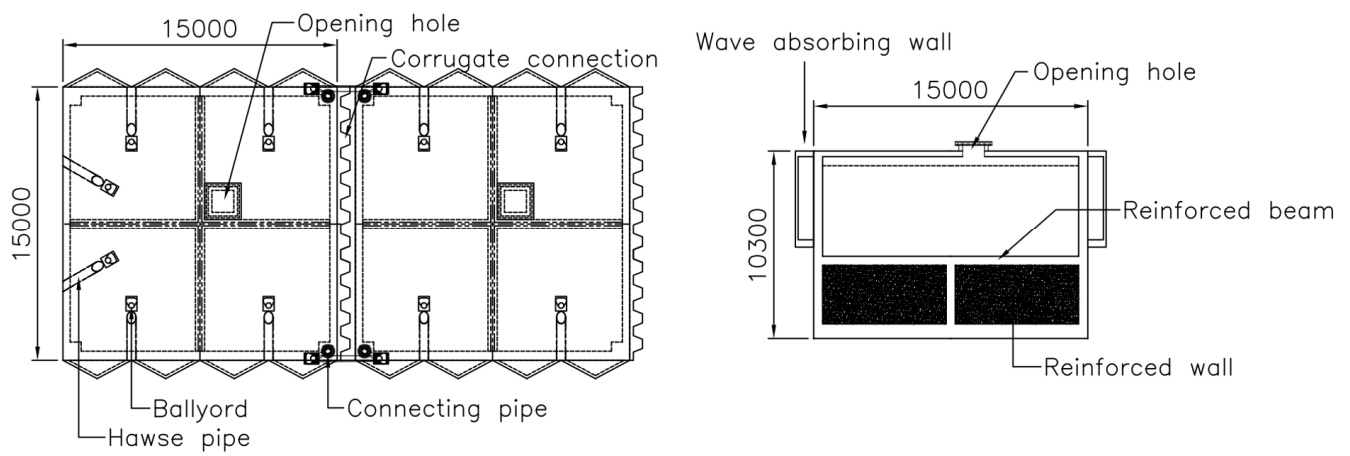

(a) Plan and elevation of unit I
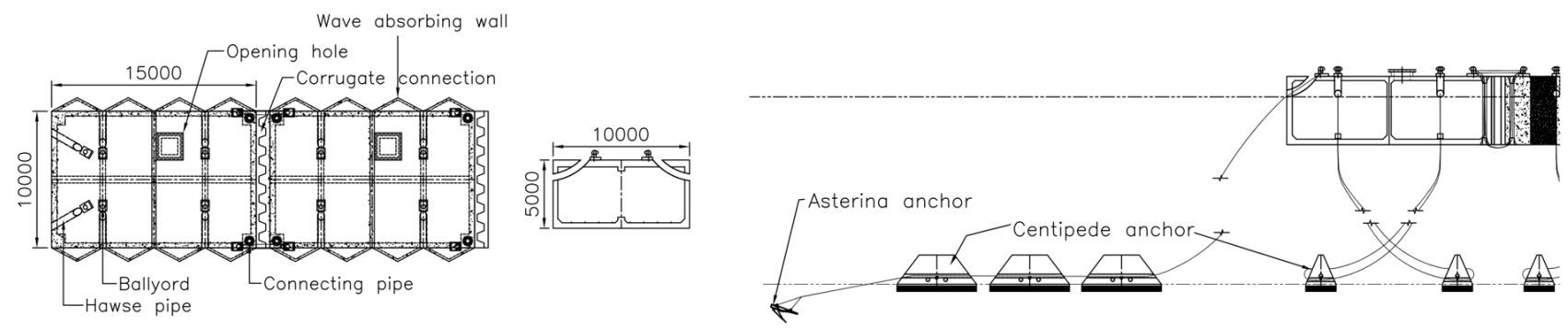

(b) Plan, elevation, and anchor connections of unit II

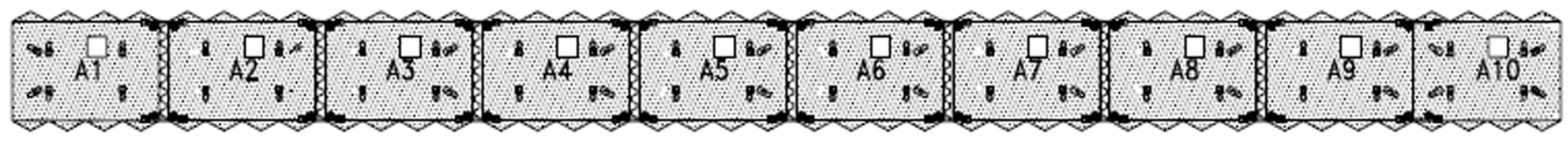

(c) Plan of complete assembly of unit I or unit II

Fig. 4 Unit details and assembly of units

(Corrugate connection) 등을 포함한다. 이를 도식화하여 Fig. 4에 나타내었다.

\section{3. 부유식 방파제 해석 및 검증}

\section{1 동유체력 산정}

본 연구에서는 범용 해양 구조물 해석 소프트웨어 SACS 5.6

V8I SELECT series 3 Version 5.6.0.8을 사용하여 Table 1에 제시
된 파랑 조건 및 파향의 일부에 대하여 동수력을 구현하였다 (Fig. 5). 이때 부유식 방파제가 계류선에 의하여 스프링 지지되 었다고 가정하고 $\mathrm{SACS}$ 를 이용하여 구조물을 모델링 하였다. 파 입사각 0 도 및 22.5 도에 대하여 수계산 파력과 SACS를 이용한 파력을 비교하여 Table 4에 제시하였다. 수계산 결과와 SACS를 통한 하중 계산 결과가 비교적 잘 일치하는 것을 확인할 수 있 다. 이로부터 수계산의 신뢰성을 검증할 수 있었다.

Table 5 및 Table 6은 두가지 해상 상태와 모든 파향을 고려한

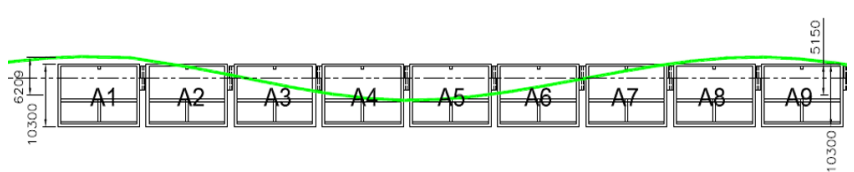

(a) Normal condition

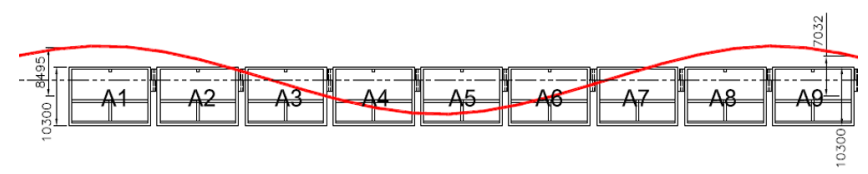

(b) Extreme condition

Fig. 5 Samples of incident wave profiles on assembly of unit I

Table 4 Comparison of wave load by manual calculation and SACS

\begin{tabular}{cccccccccccccc}
\hline \hline & Item & & A1 & A2 & A3 & A4 & A5 & A6 & A7 & A8 & A9 & A10 \\
\hline \multirow{2}{*}{$\begin{array}{c}\text { M } \\
\text { degree }\end{array}$} & Manual Cal. & $F_{x}$ & 20.8 & 295.7 & 328.7 & 99.6 & -74.3 & -254.3 & -316.7 & -81.4 & 90.5 & 328.2 \\
& SACS & $F_{x}$ & 23.28 & 285.75 & 370.06 & 209.09 & -91.61 & -323.56 & -355.68 & -146.16 & 155.96 & 351.16 \\
\hline \multirow{2}{*}{$\begin{array}{c}22.5 \\
\text { degree }\end{array}$} & \multirow{2}{*}{ Manual Cal. } & $F_{x}$ & 15.96 & 255.46 & 339.20 & 185.93 & 11.08 & -167.01 & -330.55 & -284.48 & -30.11 & 183.01 \\
& & $F_{y}$ & 6.61 & 105.82 & 140.50 & 77.01 & 4.59 & -69.18 & -136.92 & -117.83 & -12.47 & 75.81 \\
& \multirow{2}{*}{ SACS } & $F_{x}$ & 21.51 & 249.91 & 343.90 & 245.50 & 1.63 & -235.16 & -342.09 & -261.79 & -24.77 & 217.79 \\
& & $F_{y}$ & 8.91 & 103.52 & 142.45 & 101.69 & 0.68 & -97.41 & -141.70 & -108.44 & -10.26 & 90.21 \\
\hline
\end{tabular}


Table 5 Hydrodynamic forces acting on the Unit I

\begin{tabular}{ccccccccccccc}
\hline \hline & Item & & A1 & A2 & A3 & A4 & A5 & A6 & A7 & A8 & A9 & A10 \\
\hline & $F_{x}$ & 204.0 & 2900.8 & 3327.6 & 1940.4 & 973.2 & 568.0 & 488.5 & 340.4 & 887.8 & 3219.6 \\
& Degree & 0 & 0 & 22.5 & 45.0 & 0 & 67.5 & 67.5 & 67.5 & 0 & 0 \\
Normal & $F_{y}$ & 127.5 & 1037.9 & 2310.3 & 1940.4 & 1543.1 & 1371.4 & 1180.1 & 823.1 & 493.4 & 743.6 \\
{$[\mathrm{kN}]$} & Degree & 67.5 & 22.5 & 45.0 & 45.0 & 67.5 & 67.5 & 67.5 & 67.5 & 67.5 & 22.5 \\
& $F_{z}$ & 7408.5 & 7408.5 & 7408.5 & 7408.5 & 7408.5 & 7408.5 & 7408.5 & 7408.5 & 7408.5 & 7408.5 \\
& Degree & 90.0 & 90.0 & 90.0 & 90.0 & 90.0 & 90.0 & 90.0 & 90.0 & 90.0 & 90.0 \\
\hline & $F_{x}$ & 275.7 & 3277.5 & 5681.0 & 2211.2 & 1100.7 & 964.3 & 739.7 & 440.5 & 1390.1 & 3446.3 \\
& Degree & 0 & 22.5 & 22.5 & 45.0 & 67.5 & 67.5 & 67.5 & 67.5 & 0 & 0 \\
Extreme & $F_{y}$ & 217.8 & 719.1 & 2314.2 & 2211.2 & 2657.5 & 2876.3 & 1785.4 & 1063.4 & 529.7 & 258.0 \\
& Degree & 67.5 & 45.0 & 45.0 & 45.0 & 67.5 & 67.5 & 67.5 & 67.5 & 67.5 & 67.5 \\
& $F_{z}$ & 13065 & 13065 & 13065 & 13065 & 13065 & 13065 & 13065 & 13065 & 13065 & 13065 \\
& Degree & 90.0 & 90.0 & 90.0 & 90.0 & 90.0 & 90.0 & 90.0 & 90.0 & 90.0 & 90.0 \\
\hline
\end{tabular}

Table 6 Hydrodynamic forces acting on the Unit II

\begin{tabular}{ccccccccccccc}
\hline \hline \multicolumn{1}{c}{ Item } & & A1 & A2 & A3 & A4 & A5 & A6 & A7 & A8 & A9 & A10 \\
\hline & $F_{x}$ & 65.7 & 797.6 & 1127.2 & 649.4 & 286.5 & 224.6 & 157.0 & 79.5 & 225.6 & 853.5 \\
& Degree & 0 & 0 & 22.5 & 45.0 & 67.5 & 67.5 & 67.5 & 67.5 & 0 & 0 \\
Normal & $F_{y}$ & 55.9 & 324.7 & 779.9 & 649.4 & 691.6 & 542.5 & 378.7 & 193.3 & 74.6 & 192.3 \\
{$[\mathrm{kN}]$} & Degree & 67.5 & 45.0 & 45.0 & 45.0 & 67.5 & 67.5 & 67.5 & 67.5 & 67.5 & 67.5 \\
& $F_{z}$ & 4672.5 & 4672.5 & 4672.5 & 4672.5 & 4672.5 & 4672.5 & 4672.5 & 4672.5 & 4672.5 & 4672.5 \\
& Degree & 90.0 & 90.0 & 90.0 & 90.0 & 90.0 & 90.0 & 90.0 & 90.0 & 90.0 & 90.0 \\
\hline & $F_{x}$ & 102.0 & 1103.6 & 1739.3 & 545.4 & 369.8 & 381.6 & 186.4 & 20.6 & 347.3 & 1191.9 \\
& Degree & 22.5 & 22.5 & 22.5 & 45.0 & 67.5 & 67.5 & 67.5 & 67.5 & 0 & 0 \\
Extreme & $F_{y}$ & 95.2 & 314.9 & 615.1 & 572.9 & 893.7 & 922.1 & 449.3 & 50.0 & 0 & 334.5 \\
& Degree & 67.5 & 45.0 & 45.0 & 67.5 & 67.5 & 67.5 & 67.5 & 67.5 & 67.5 & 22.5 \\
& $F_{z}$ & 8442.5 & 8442.5 & 8442.5 & 8442.5 & 8442.5 & 8442.5 & 8442.5 & 8442.5 & 8442.5 & 8442.5 \\
& Degree & 90.0 & 90.0 & 90.0 & 90.0 & 90.0 & 90.0 & 90.0 & 90.0 & 90.0 & 90.0 \\
\hline
\end{tabular}

계산된 최대 파력의 최대치를 나타낸다. 또한, 파력의 최대치가 발생한 입사각을 동시에 제시하였다.

\section{2 소재에 따른 응력 분석}

부유식 방파제 소재(강재 및 콘크리트) 및 부유체 크기(유닛 I 및 유닛 II)에 따른 구조 안전도 평가를 위하여 SACS를 사용 한 구조 해석을 실시하였다. 즉, 부유식 방파제의 재질이 강재 일 경우와 콘크리트일 경우로 나누어 구조 해석을 수행하였다. 이때 적용한 산업 규격은 AISC 9판(AISC, 1989) 및 API WSD 21판(API, 2000)이었다.

1 세트( 10 개 유닛)의 거동을 동시에 분석하기 위하여 Fig. 6에 보인 바와 같이 한 개의 유닛을 보 요소로 모델링 하였다. 또한, 유닛 간의 연결을 위하여 별도의 연결 보 요소를 이용하였으며, 유닛간의 상대적인 운동이 가능하도록 연결 보요소의 $y$ 방향 및 $z$ 방향 회전 $\left(R_{y}\right.$ 및 $\left.R_{z}\right)$ 자유도를 제거하였다. 유닛 I 과 유닛 II의 중량은 밀도를 조정함으로서 설계 중량을 유지할 수 있었다. 특히 유닛 I은 유닛 내부에 평형수를 포함하므로 이를 포함하도록 중량을 보정하였다.
부유체 유닛 한 개당 4 개의 계류선이 연결되며, 이 연결점에 스프링 요소를 배치하여 경계 조건을 형성하였다. 스프링 요소 의 강성은 준정적 계산을 통해서 $1 \mathrm{kN} / \mathrm{m}$ 의 강성을 부여하였다. 콘크리트 및 강재의 항복 강도는 각각 $48 \mathrm{MPa}$ 및 $235 \mathrm{MPa}$ 이었으 며, 재질별 부분 안전 계수를 5.0 으로 가정하였다.

최대 파력이 발생한 파향 $0^{\circ}$ 와 $67.5^{\circ}$ 에 구조 해석을 수행하였 다. Fig. 6 및 Fig. 7은 각각 소재가 강재 및 콘크리트일 경우 유 닛 사이의 수직 운동이 가장 잘 모사되는 $0^{\circ}$ 입사각에 대한 결과 를 나타낸다. 일차원 부재에 대한 강도 평가를 위하여 통상 유 니티(Unity)를 많이 사용한다. 유니티는 발생한 응력(하중)을 강 도(임계 하중)으로 나눈 값이다. 여기서 강도는 통상 항복 강도 에 안전 계수를 고려한 허용 응력 등을 의미한다. 강재 모델의 유니티는 최대 0.32 (유닛 I) 및 0.12 (유닛 II)였으며, 반면 콘크리 트 모델에서 유니티는 최대 0.7 (유닛 I) 및 0.31 (유닛 I)이었다. 부유체의 크기가 감소하면서 동유체력이 감소하여 작은 유니티 를 나타낸 것으로 추정된다. 또한, 강재 및 콘크리트 모두 유니 티가 1.0 을 초과하지 않았기 때문에 적절한 소재로 판단된다. 


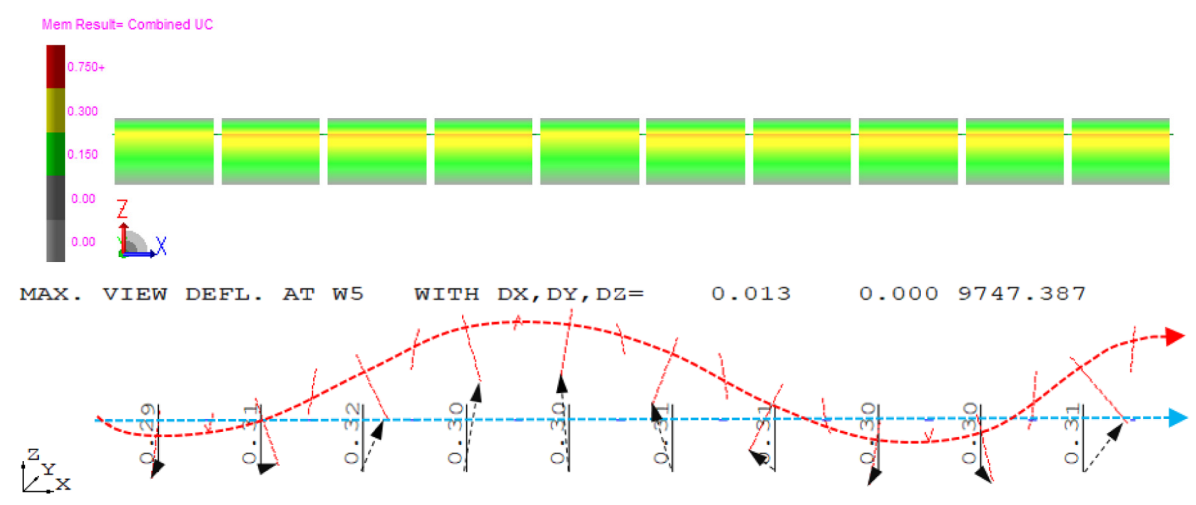

(a) Unit I

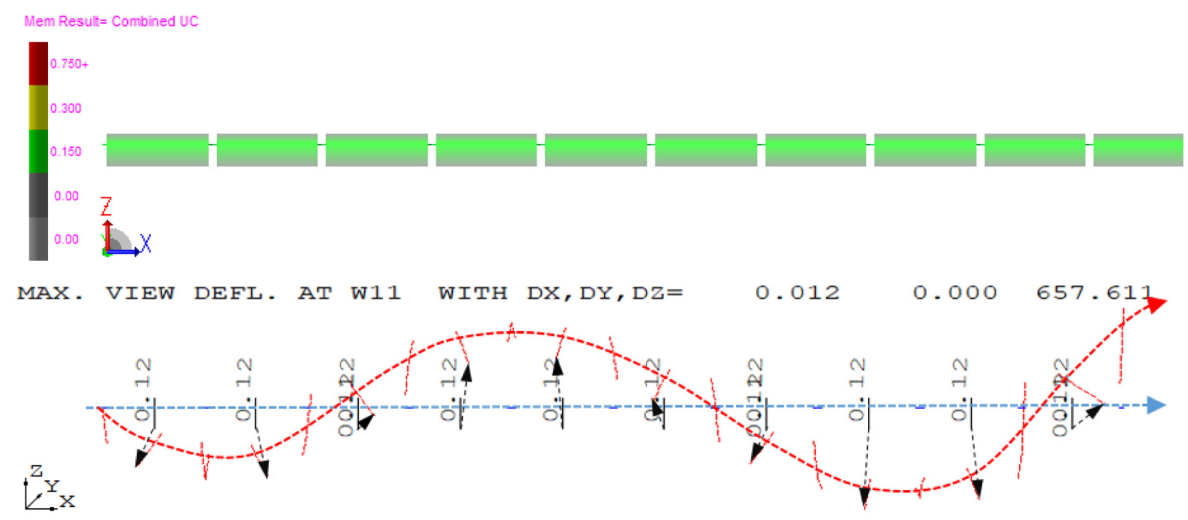

(b) Unit II

Fig. 6 Steel model with unity results for $0^{\circ}$ incident wave angle
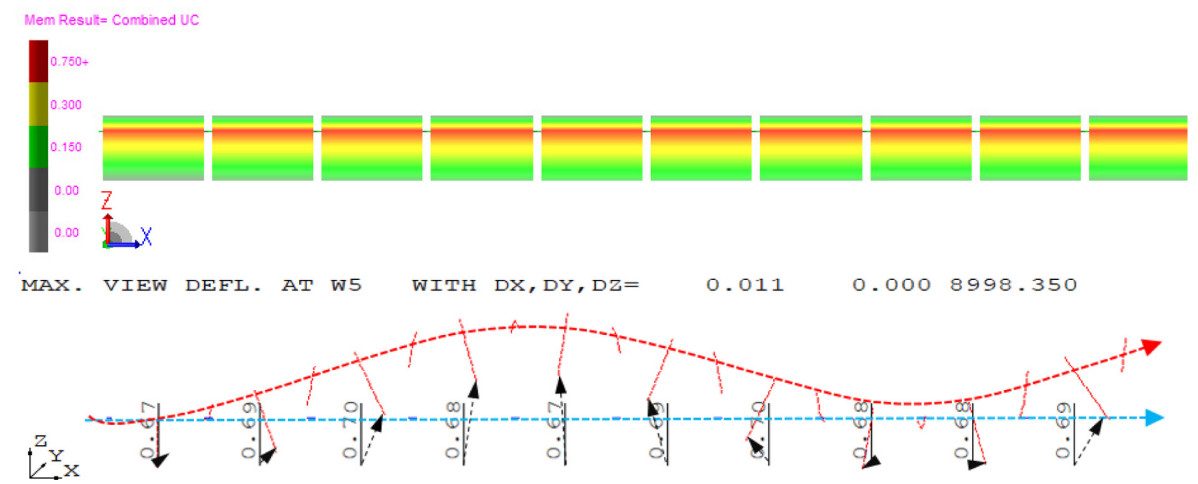

(a) Unit I
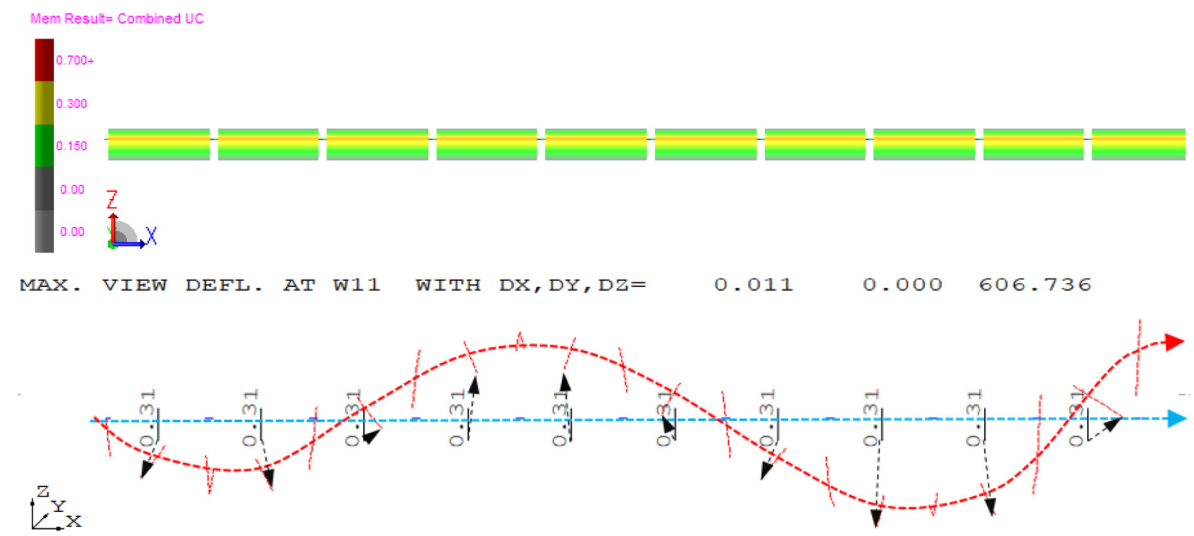

(b) Unit II

Fig. 7 Concrete model with unity results for $0^{\circ}$ incident wave angle 


\section{4. 모형 실험 (Model Tests)}

\section{1 닺 모형 육상 압흔 실험}

본 연구에서 설계 개발하고자 하는 부유체의 위치 유지를 위 한 닺의 파지력을 확인하기 위하여 모형을 제작하여 육상 실험 을 수행하였다. 닺은 실물 크기의 $1 / 30$ 로 축소 제작되었다. 즉 모형 투묘 닺의 크기는 $200 \mathrm{~mm} \times 200 \mathrm{~mm} \times 150 \mathrm{~mm}$ 였다(Fig. 8(b)). 또한, 마찰 계수(Friction coefficient)와 압흔(Dropped depth)이 극대화되 는 형상을 결정하기 위하여 Fig. 8(a)에 보는 바와 같이 요철 문 양(원형, 사각형, 격자형 등)에 따라 6개의 형상을 선정하였다. 모형 투표 닻의 중량은 약 $12 \sim 14 \mathrm{~kg}$ 이었다.

육상 압흔 실험은 마찰 계수를 측정하기 어려운 수조 실험을 보완하기 위하여 육상에서 실시되었다. 실제 해저면 토질 조건 에 따른 투묘 닺의 파지력 특성을 분석하고자, 토사의 깊이와 폭을 각각 $30 \mathrm{~cm}$ 및 $100 \mathrm{~cm}$ 로 평탄화시킨 후 $50 \mathrm{~cm}$ 높이에서 닻 을 자유 낙하하여 압흔 깊이를 측정하였다. 이때 국내에서 일반 적으로 얻을 수 있는 토사를 사용하였으며, 토사에 대한 별도의 물성 실험은 수행되지 않았다. 토사의 배수도(Drainage)에 따른 편차를 없애기 위하여 압흔 실험은 3 시간 이내에 모두 수행되 었다.
Table 7은 닺의 6가지 유형에 대한 육상 자유 낙하 결과를 나 타낸다. 이 값은 3회 자유 낙하 실험에 대한 평균값이다. 유형 $\mathrm{F}$ 가 가장 큰 압흔 깊이를, 유형 $\mathrm{A}$ 가 두 번째로 큰 압흔 깊이를 나타내었다. Fig. 9는 이 두 유형에 대한 압흔 계측 사진을 나타 낸다.

\section{2 닺 모형 수조 예인 실험}

국립수산과학원의 3 차원 조파 수조에서 닺의 예인 실험이 실 시되었다. 국립수산과학원 수조는 총 길이 $85 \mathrm{~m}$, 폭 $10 \mathrm{~m}$, 깊이는 $3.5 \mathrm{~m}$ 이며 최고 파고는 $0.5 \mathrm{~m}$ (주기: $0.5 \sim 3$ 초)이다. 수조 예인 실험 은 유형별 닺을 예인 전차에 한 개씩 연결한 후 예인하여 $1 \mathrm{~m} / \mathrm{s}$ 의 속도로 30 초 동안 예인 실험하였다. 한 개의 유형에 대하여 3 회의 예인 실험이 수행되었다. 예인 시작 후 5 24초 동안 마찰 력에 의한 인장력을 측정하였다. 측정된 인장력 이력의 분포를 살펴본 결과 정규 분포를 잘 따르고 있음을 확인할 수 있었다 (Fig. 10).

Fig. 10 의 데이터를 활용하여 파지력의 평균과 표준 편차를 구하여 Table 8 에 제시하였다. 유형 A, F, D 순으로 파지력 평균 값의 순서를 나타내었다. 표준 편차의 수준은 평균 대비 비교적 작다는 점을 Fig. 10 및 Table 8에서 동시에 확인 가능하다.

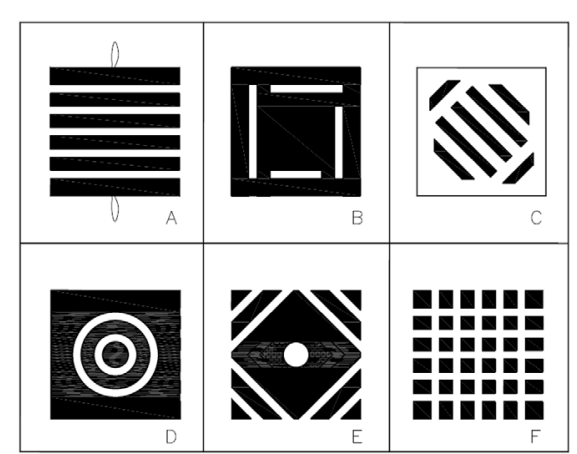

(a) Six types of anchor
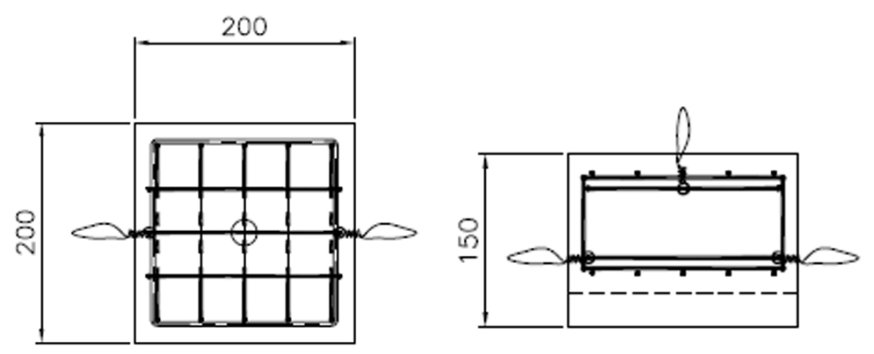

(b) Anchor dimensions

Fig. 8 Types and dimensions of model anchors (unit: mm)

Table 7 Result of dropped depth by 6 anchor type by land tests

\begin{tabular}{ccccccc}
\hline \hline Items & A & B & C & D & E & F \\
\hline Dropped depth $[\mathrm{cm}]$ & 3.6 & 3.0 & 1.6 & 3.4 & 2.6 & 3.8 \\
\hline
\end{tabular}

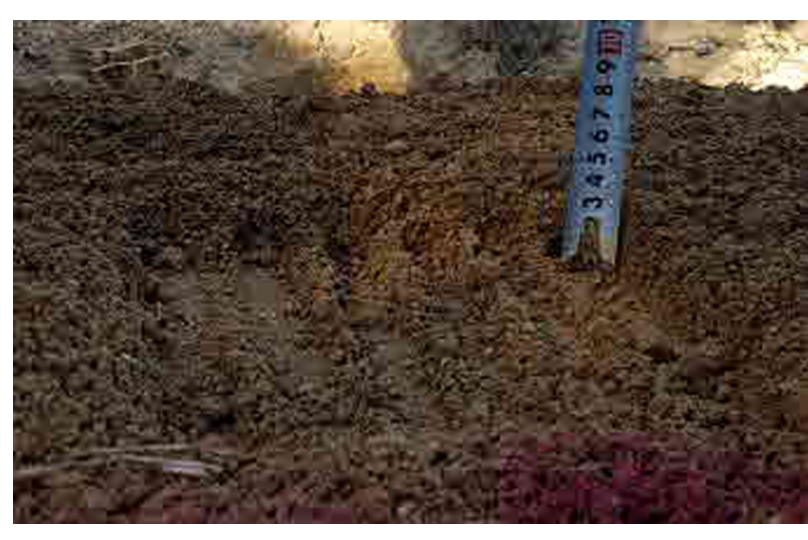

(a) Type A anchor

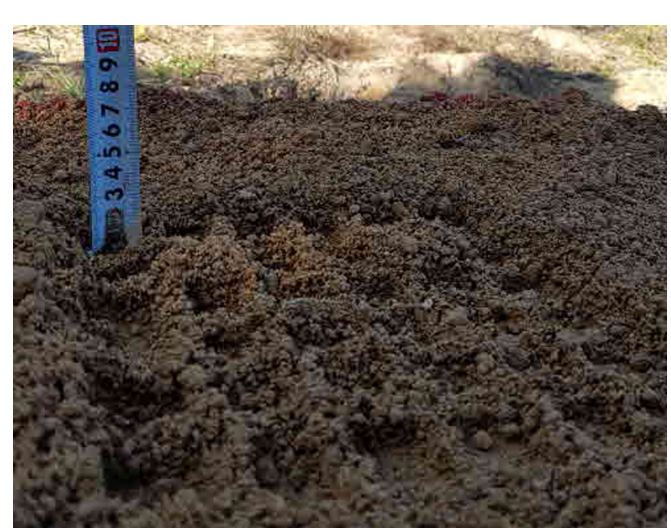

(b) Type F anchor

Fig. 9 Photos of dropped depths for model anchor type A and F 


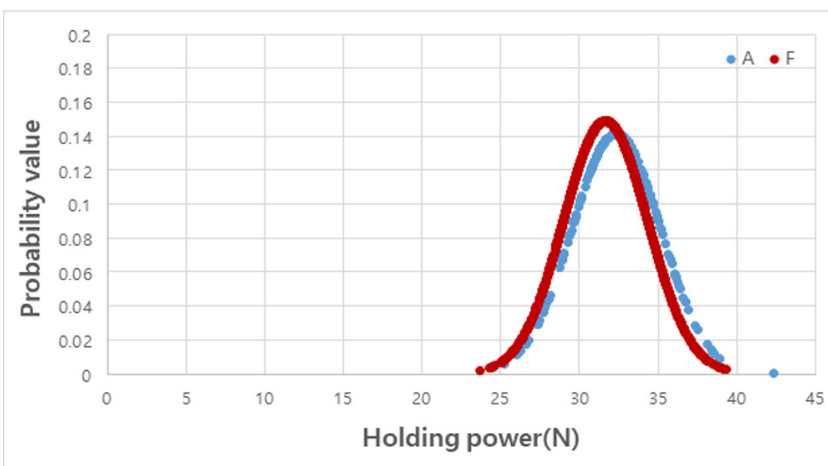

(a) Type $\mathrm{A}$ and $\mathrm{F}$ anchors

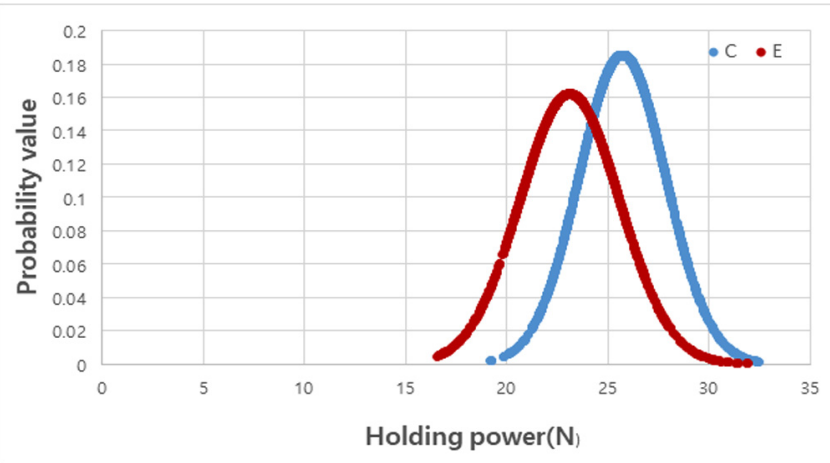

(b) Type $\mathrm{C}$ and $\mathrm{E}$ anchors

Fig. 10 Normal distribution curve of anchor by towing tank tests

Table 8 Results of towing force tests of 6 types of anchors

\begin{tabular}{ccccccc}
\hline \hline Items & A & B & C & D & E & F \\
\hline Anchor weight $[\mathrm{kgf}]$ & 13.2 & 14.0 & 12.0 & 13.5 & 12.7 & 12.5 \\
Average of towing force $[\mathrm{N}]$ & 32.35 & 28.99 & 25.72 & 29.86 & 23.12 & 31.66 \\
Standard deviation of towing forces [N] & 2.82 & 5.62 & 2.15 & 3.92 & 2.46 & 2.68 \\
\hline
\end{tabular}

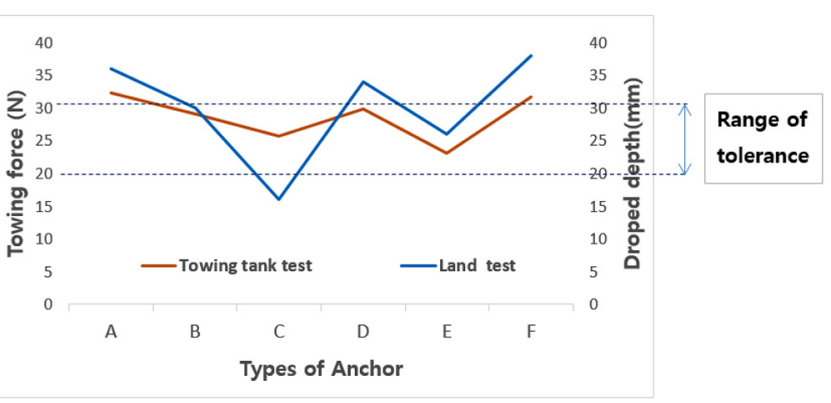

Fig. 11 Comparison of towing tank tests \& land free drop tests

파지력 평균의 관점에서 유형 $\mathrm{A}$ 가 가장 우수하며, 표준 편차 도 상당히 적어서 데이터의 신뢰성도 높다고 볼 수 있다. 반면, 육상 압흔 실험에서는 유형 $\mathrm{F}$ 가 가장 우수한 성능을 보여주었 다. 육상 압흔 실험과 수조 예인 실험 결과를 비교하기 위하여 유형에 따른 압흔 깊이와 파지력 평균을 Fig. 11에 제시하였다. 이로부터 파지력 평균과 압흔 깊이는 상관관계가 있다는 점을 확인할 수 있었다. 유형 $\mathrm{A}, \mathrm{D}, \mathrm{F}$ 가 압흔 깊이 및 파지력 관점에 서 우수한 것으로 결론 내릴 수 있었다.

\section{5. 부유식 방파제의 경제성 평가}

욕지도 해역에 필요한 부유식 방파제 총 길이 $400 \mathrm{~m}$ 로 산정할 때 유닛 I 과 유닛 II 의 CAPEX(Capital expenditure)를 Table 9에 제
시하였다. 강재로 제작할 경우 부유식 방파제 길이 $15 \mathrm{~m}$ 제작시 약 $300 \mathrm{t}$ 중량이 소요되었던 사례로부터 비용을 산정하였다. 콘크 리트로 제작할 경우 비용은 2019년 하반기 건설 분야별 평균 임금 현황 등을 반영하였으며 일부 공사 사례를 참고하여 산정하였다. 즉, 유닛 I 에 강재를 적용할 경우 $1 \mathrm{~m}$ 당 1 억 원이 소요되어 1 개 유닛 제작시 15 억 원, $400 \mathrm{~m}$ 제작시 375 억이 필요하였다. 반면 콘 크리트 재질은 1 유닛 기준 7.7억 원이며, 25 개 유닛은 192 억이 소 요될 것으로 조사되었다. 유닛 II 를 콘크리트로 제작할 경우 유닛 당 3.8 억원, $400 \mathrm{~m}$ 비용은 95 억이 소요되는 것으로 조사되었다. 결 론적으로 부유식 방파제를 강재로 제작할 경우 콘크리트 재질에 비하여 강재가 약 1.9 4배 더 높을 것으로 예상된다.

Table 10은 부유식 방파제의 수명 25년을 기준으로 했을 경우 의 OPEX(Operating expenditure)를 나타낸 것이다. 강재는 해상 부식 환경에 대응하기 위해 5년마다 완전 방식이 필요하여 20 만 원/m이 소요되며, 콘크리트 또한 해수로부터 보호를 위한 코 팅작업이 필요한데 1 만 원 $/ \mathrm{m}$ 정도로서 20 배 저렴하다. 유닛 I 의 경우 부유식 방파제 전체 $400 \mathrm{~m}$ 를 유지하기 위해서는 강재는 3.8 억 원이 필요하였으며, 콘크리트는 0.19 억 원으로 재질상 유 닛 I 은 약 3.6 억원 유닛 II 는 3.7 억원 유지비용이 차이가 있는 것으로 나타났다. 재질별 제작-설치·운영비를 볼 때, 부유식 방파제의 규모가 커질수록 콘크리트가 더 경제적인 것으로 나 타났으며, 구조적·재질적으로 콘크리트의 단점을 보완할 수 있는 정도의 조인트 재질을 조합함으로써 경제성과 효율성을 가진 부유식 방파제를 제작할 수 있을 것으로 예측할 수 있다.

Table 9 CAPEX analysis result of installation in terms of material types

\begin{tabular}{|c|c|c|c|c|}
\hline Items & \multicolumn{2}{|c|}{ Unit I (unit: $1,000 \mathrm{KRW}$ ) } & \multicolumn{2}{|c|}{ Unit II (unit: $1,000 \mathrm{KRW}$ ) } \\
\hline Steel @ & $1,500,000 /$ Unit $\times 25$ Unit/Total & $=37,500,000 /$ Total & $1,500,000 /$ Unit $\times 25$ Unit/Total & $=37,500,000 /$ Total \\
\hline Concrete (b) & $766,600 /$ Unit $\times 25$ Unit/Total & $=19,165,000 /$ Total & $377,464 /$ Unit $\times 25$ Unit/Total & $9,436,600 /$ Total \\
\hline & Profit on concrete (a-b) & $\begin{array}{r}733,400 / \text { Unit } \\
18,335,000 / \text { Total }\end{array}$ & Profit on concrete (a)-(b) & $\begin{array}{r}\text { 1,122,536/Unit } \\
28,063,400 / \text { Total }\end{array}$ \\
\hline
\end{tabular}


Table 10 OPEX analysis result of maintenance in terms of material types

\begin{tabular}{|c|c|c|c|c|}
\hline Items & \multicolumn{2}{|c|}{ "Unit I (unit: 1,000 KRW, per 25 year) } & \multicolumn{2}{|c|}{ "Unit II (unit: 1,000 KRW, per 25 year) } \\
\hline $\begin{array}{l}\text { Steel } \\
\text { (a) }\end{array}$ & $\begin{array}{c}200 \mathrm{KRW} / \mathrm{m} \cdot \text { time } \times 15 \mathrm{~m} / \text { Unit } \times 5 \text { times } \\
15,000 \mathrm{KRW} / \text { Unit } \times 25 \text { Unit/Total }\end{array}$ & $\begin{array}{l}=15,000 / \text { Unit } 200 \\
=375,000 / \text { Total }\end{array}$ & $\begin{array}{l}0 \mathrm{KRW} / \mathrm{m} \cdot \text { time } \times 15 \mathrm{~m} / \text { Unit } \times 5 \text { times } \\
15,000 \mathrm{KRW} / \text { Unit } \times 25 \text { Unit/Total }\end{array}$ & $\begin{array}{l}=15,000 / \text { Unit } \\
=375,000 / \text { Total }\end{array}$ \\
\hline $\begin{array}{l}\text { Concrete } \\
\text { (b) }\end{array}$ & $\begin{array}{c}10 \mathrm{KRW} / \mathrm{m} \cdot \text { time } \times 15 \mathrm{~m} / \text { Unit } \times 5 \text { times } \\
750 \mathrm{KRW} / \text { Unit } \times 25 \text { Unit/Total }\end{array}$ & $\begin{array}{l}=\quad 750 / \text { Unit } 5 \\
=18,750 / \text { Total }\end{array}$ & $\begin{array}{l}\mathrm{KRW} / \mathrm{m} \cdot \text { time } \times 15 \mathrm{~m} / \text { Unit } \times 5 \text { times } \\
375 \mathrm{KRW} / \mathrm{Set} \times 25 \text { Unit } / \text { Total }\end{array}$ & $\begin{array}{l}=\quad 375 / \text { Unit } \\
=\quad 9,375 / \text { Total }\end{array}$ \\
\hline & Profit on concrete (a-b) & $\begin{array}{r}14,250 \text { / Unit } \\
356,250 / \text { Total }\end{array}$ & Profit on concrete (a)-(b) & $\begin{array}{r}14,625 \text { / Unit } \\
365,625 \text { / Total }\end{array}$ \\
\hline
\end{tabular}

\section{6. 결 론}

본 연구에서는 국내 연근해에 적용할 수 있는 콘크리트 부유 식 방파제를 개발하기 위해 현장 조사, 부유식 방파제 기본 설 계 및 해석, 모형 실험, 경제성 분석을 실시하였다. 대형 제원 (유닛 I)의 경우 대파고 및 대수심(40 50m)에서 대응할 수 있도 록 소파벽, 파형 접합 등 상세 구조 설계를 실시하였다.

개발하고자 하는 부유식 방파제의 설계 검증을 위해 현장 실 측 자료와 극한 해상 조건을 기준으로 5 개 파향에 대한 동수력 을 수계산으로 산정하였으며, 이를 SACS 해석을 통하여 검증하 였다. 또한, SACS 해석을 통하여 소재와 유닛의 크기에 따른 강도 평가를 실시하였다. 콘크리트를 소재로 하는 부유식 방파 제에서 높은 유니티가 발생하였지만, 허용치를 초과하지 않아 서 콘크리트 부유식 방파제는 구조적으로 안전할 것으로 판단 하였다.

투묘식 콘크리트 닺을 $1 / 30$ 로 축소하여 표면 요철에 따른 육상 압흔 실험을 실시하였다. 이로부터 요철 문양에 따른 특성을 실험 적으로 검증하였다. 또한 동일한 모형 닺에 대하여 수조 예인 실 험을 실시하여 최종적으로 우수한 성능의 닺을 제시하였다.

부유식 방파제의 재질에 따른 경제성 분석(CAPEX 및 OPEX) 를 실시하였다. CAPEX 차원에서는 강재의 원가가 최대 2 배 정 도 상승하였으며, $\mathrm{OPEX}$ 차원에서도 강재보다는 콘크리트 재질 이 경제적일 것으로 추정되었다. 부유식 방파제의 총연장이 길 어질수록 비용의 차이는 더욱 현저할 것으로 추정되었다.

향후 부유식 방파제에 대한 정밀한 운동성능 시뮬레이션을 통하여 하중 RAO의 도출이 요구된다. 이 결과를 바탕으로 응력 $\mathrm{RAO}$ 를 도출하는 통계적 계산을 통하여 콘크리트 재료의 부유 식 방파제에 대한 구조 안전도 검증이 요구된다. 또한, 월파시 에 경험하는 부유식 방파제의 운동 및 구조 성능에 대한 엄밀 한 검증이 요구된다.

\section{후기}

본 연구는 국립수산과학원 지원으로 수행된 연구결과 일부임 을 밝히며, 연구비 지원에 감사드립니다.

\section{References}

American Institute of Steel Construction, inc. (AISC), 1989. Specification for Structural Steel Buildings. AISC $9^{\text {th }}$ Edition.
American Petroleum Institute (API), 2000. Recommended Practice for Planning, Designing, and Constructing Fixed Offshore Platforms-Working Stress Design. API WSD $21^{\text {st }}$ Edition.

Cho, I.H., 2002. Wave Control Performance of Moored Pontoon-Type Floating Breakwater. Journal of the Korean Society for Marine Environmental Engineering, 5(3), 35-44.

Fox, R.W., McDonald, A.T., Pritchard, P.J., Mitchell, J.W., 2017. Fluid Mechanics. $9^{\text {th }}$ Edition, Textbooks.

Jeong, Y.J., Hwang, Y.K., Park, M.S., Lee, B.C., Kim, B.C., 2013. Development of Structural System of Hybrid Floating Structure. Korea Institute of Civil Engineering and Building Technology. Jung, D.H., Kim, H.J., Kim, J.H., Moon, D.S., 2006. A Preliminary Experiment Study for Development of Floater of Floating Breakwater. Journal of the Korean Society for Marine Environmental Engineering, 9(3). 141-147.

Kim, D.S., Park, K.S., Jeong, M.Y., Park, D.C., 2007a. Characteristics of Floating Breakwaters Constructed on the Front of Sea Pasture of Tongyeong City. Proceedings of Korean Society of Civil Engineers Regular Conference, 646-649.

Kim, D.S., Nakamura, T., Park, W.M., Kim, T.G., $2007 \mathrm{~b}$. Characteristics of Floating Breakwaters Being Constructed at the Weonjeon Fishing Port of Masan City. Proceedings of Korean Society of Civil Engineers Regular Conference, 654-657.

Koh, K.T., Jnag, I.Y., Kim, S.W., Lee, K.M., 2004. Kwang Myong, Materials and Construction of Off-Shore Concrete Structures. Magazine of the Korea Concrete Institute, 16(6), 26-30. https://doi.org/10.22636/MKCI.2004.16.6.26

Lee, S.G, 2012, Ship Calculation and Stability. GSintervision. Lee, S.J, 2014, Introduction to Marine Hydrodynamics. GSintervision. Link, R.A., Elwi, A.E., 1995. Composite Concrete-Steel Plate Walls: Analysis and Behavior. Journal of Structural Engineering ASCE, 121(2), 260-271. https://doi.org/10.1061/(ASCE)0733-9445(1995) 121:2(260)

Park, Y.H., Youn, D.O., 2016. Development of a New Armor Unit against High Waves. Korea Academy Industrial Cooperation Society, 17(6), 737-743. https://doi.org/10.5762/KAIS.2016.17. 6.737

Society of Naval Architects and Marine Engineers (SNAME), 1991. Principles of Naval Architecture. 